\title{
Alpha-lipoic acid attenuates iron overload- induced structural changes in the liver of the laboratory mouse (Mus musculus)
}

\author{
William O. Sibuor, Fidel O. Gwala, Jeremiah K. Munguti, Moses M. Obimbo \\ Department of Human Anatomy, School of Medicine, University of Nairobi, Nairobi, Kenya
}

\begin{abstract}
Objectives: The role of alpha-lipoic acid in the amelioration of iron overload-induced hepatic damage remains largely underexplored. Therefore, this paper aimed at describing the structural effects of alpha-lipoic acid on the liver following iron overload in mice.

Methods: After ethical approval, a total of 24 male mice were used. Twenty mice were randomly divided into two groups: A and B. Group A rats received $50 \mathrm{mg} / \mathrm{kg}$ of iron dextran intraperitoneally daily for 49 days, while those in Group B received a daily oral dose of $100 \mathrm{mg} / \mathrm{kg}$ alpha-lipoic acid by gavage in addition to the treatment in Group A. Four mice were used as normal controls. At the endpoint of the experiment, the livers were harvested and studied for iron deposition, parenchymal histoarchitecture and hepatocyte densities. Photomicrographs were taken using a digital photomicroscope for morphometric analysis.

Results: Treatment of mice with iron led to a distortion of the histoarchitecture of the liver which was attenuated with co-administration of alpha-lipoic acid. Additionally, co-treatment of iron with alpha-lipoic acid resulted in significant lowering of hepatic iron deposition $(p<0.001)$, reduction in leukocyte infiltration and significantly greater hepatocyte densities $(p<0.001)$.
\end{abstract}

Conclusion: Alpha-lipoic acid considerably attenuates the structural damage in the liver induced by iron overload.

Keywords: alpha-lipoic acid; iron; liver

Anatomy 2018;12(3):118-123 @2018 Turkish Society of Anatomy and Clinical Anatomy (TSACA)

\section{Introduction}

Iron overload is a common clinical problem that occurs in conditions such as hereditary hemochromatosis and transfusion dependent anaemia including sickle cell disease and beta thalassemia. ${ }^{[1,2]}$ Since the liver is the main storage site for iron, it is among the key organs to be adversely affected by iron overload toxicity resulting in hepatic fibrosis and hepatocellular necrosis. ${ }^{[3,4]}$

Currently, management of iron overload involves iron chelation therapy and phlebotomy. These modalities however, have several limitations including high cost, patient incompliance and numerous associated side effects. ${ }^{[5-7]}$ Furthermore, phlebotomy is contraindicated in anaemic patients. ${ }^{[8]}$ Thus, there is need for better avenues to augment the management of iron overload.
Alpha-lipoic acid (ALA) is a widely available cheap but potent antioxidant. It has lately been in use in the management of diabetic polyneuropathies where it scavenges reactive oxygen species (ROS) produced as a result of glucose auto-oxidation induced by hyperglycemia. ${ }^{[9]} \mathrm{A}$ few studies have documented the possible iron chelating properties of ALA. For instance, Goralska et al. ${ }^{[10]}$ showed that treating isolated cultured lens epithelial cells with ALA significantly lowered the size of the free intracellular iron. In another study by Suh et al., ${ }^{[11]}$ feeding ALA to aged rats for 2 weeks showed a reversal of the age-related accumulation of iron in the cerebral cortex. However, these studies were conducted under conditions of normal body iron levels. Hitherto, there are hardly any studies that have investigated the effects of ALA on the liver following iron overload. This study therefore 
aimed to describe the structural effects of ALA on the liver of the mouse following iron overload.

\section{Materials and Methods}

ALA was supplied by Nature's Bounty, Inc. (Bohemia, NY, USA) while iron dextran (Dawafer) was supplied by Chongqing Fangtong for Dawa Limited (Kenya). The injections were administered using 30 gauge (BD MicroFine ${ }^{\mathrm{TM}}$ Plus; Becton Dickinson and Co., Franklin Lakes, NJ, USA) insulin syringes and a gavage tube for mice was used for oral drug administration.

A total of 24 male 8 week old mice (Mus musculus) were purchased from The Department of Zoology, University of Nairobi, Kenya. Ethical approval to conduct the study was obtained from the Animal Use and Ethics Committee, Faculty of Veterinary Medicine, University of Nairobi, Kenya. The handling and care of the animals were in accordance with the guidelines provided by the same committee.

Four mice were randomly selected for use as normal controls. One of the 4 mice selected as controls was used to show the baseline histomorphology of the liver. The remaining 20 mice were then randomly divided into two equal groups: A and B. Group A received a daily intraperitoneal (i.p.) injection of $50 \mathrm{mg} / \mathrm{kg} /$ day of iron dextran followed by daily oral gavage of $0.3 \mathrm{ml}$ of normal saline, while Group B received a daily i.p. injection of $50 \mathrm{mg} / \mathrm{kg} /$ day iron dextran followed by daily oral gavage of 100 $\mathrm{mg} / \mathrm{kg} / \mathrm{day}$ of ALA. The normal control mice were given a daily i.p. normal saline $(30 \mu l)$ followed by daily oral gavage of $0.3 \mathrm{ml}$ normal saline. The dose of iron dextran used was based on the study by Zhang et al., ${ }^{[12]}$ while that of ALA was based on the studies by Budin et al ${ }^{[13]}$ and Ahmadvand and Jamor. ${ }^{[14]}$ Three mice from each group were sacrificed at day 16 and 32 of the experiment while the remaining 4 in each group were sacrificed at day 49 .

The livers were harvested en masse and stored in 10\% formalin. Independent uniform random sampling, as described by Marcos et al. ${ }^{[15]}$ was used to select 5 random fragments from each liver for histological processing and staining with haematoxylin and eosin.

Photomicrographs of the stained sections were taken using a 12 mega pixel Canon camera mounted on a photomicroscope.

Estimation of iron deposition was done using the Cavalieri principle of point counting ${ }^{[16]}$ and data expressed as volumetric densities (\%). Following the technique described by Gundersen et al. ${ }^{[17]}$ and Bancroft and Cook, ${ }^{[18]}$ the selected histological areas were analysed using a superimposed 80-point grid on the digital images on a monitor screen using ImageJ software (National Institutes of Health, Bethesda, MD, USA) (Figure 1).
Hepatocyte density estimation was done using the Cavalieri's principle of point counting. ${ }^{[16]}$ Using the Image J software, grid squares were superimposed on the images then the cells within a square and those crossed by the inclusion line were counted (Figure 2).

Quantitative data on volumetric densities of iron deposits and hepatocyte densities was entered into the Statistical Package for Social Sciences (SPSS for Windows, version 21.0; SPSS Inc., Chicago, IL, USA) for analysis. Cell densities were expressed in $\mathrm{mm} 2$ while iron deposition was expressed as a percentage. KruskalWallis $\mathrm{H}$ test was used to compare medians of the quantitative data across the various harvesting periods within each group while Mann-Whitney $U$ test was used to compare the medians between Group A and B. A p value $\leq 0.05$ was considered significant at $95 \%$ confidence interval. Data are presented in photomicrographs and graphs.

\section{Results}

Iron treatment resulted in a progressive increase in the volumetric densities of the iron deposits from $6.4 \%$ at day 16 to $12.03 \%$ and $27.26 \%$ at days 32 and 49 , respectively $(\mathrm{p}<0.001)$. Co-administration of iron with ALA resulted in

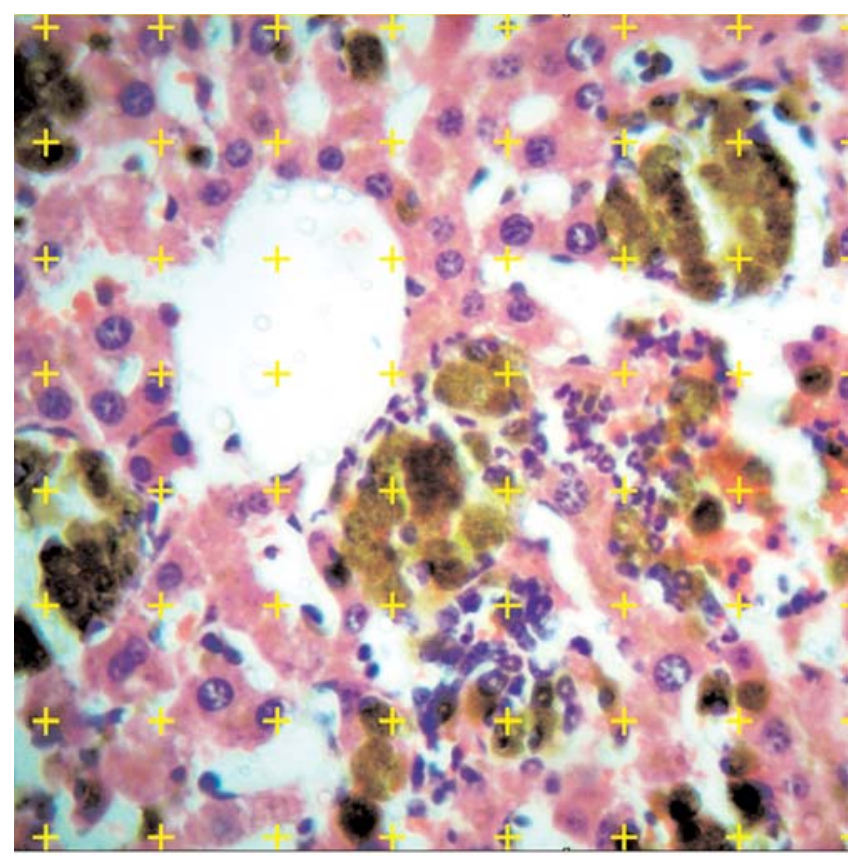

Figure 1. The point counting method to estimate the volumetric density of the iron deposits. The volume densities of the iron deposits were calculated by the formula $\mathrm{Vv}=\mathrm{Pp} / \mathrm{Pt}$, where $\mathrm{Vv}$ is the volume density, $\mathrm{p}$ is the component under consideration (iron deposits), Pp is the number of test points associated with $p$, and Pt is the total number of points of the test system. [Color figure can be viewed in the online issue, which is available at www.anatomy.org.tr] 
significantly lower volumetric densities across all the harvesting periods $(\mathrm{p}<0.001)$. The percentages in the ALA group were $3.76 \%, 7.52 \%$ and $15.79 \%$ at day 16,32 and 49, respectively (Figure 3).

Iron treatment resulted in distortion of the normal hepatic histoarchitecture proportional to the duration of treatment. There was marked degeneration of hepatocytes with distortion of the hepatocyte cords. The nuclei of hepatocytes were enlarged and showed fragmented nucleoli. There was also infiltration of deeply basophilic leukocytes around several clusters of large iron deposits.

ALA co-administration resulted in a reduction of the magnitude of the iron overload induced histoarchitectural changes as evidenced by the reduction in the sizes and area of the iron deposits. The cord like arrangement of the hepatocytes was also preserved with discernible boundaries between cells in adjacent cords. The nuclei of hepatocytes showed less enlargement and fragmentation. The leukocyte infiltrates were also reduced (Figure $4 \mathbf{a}-\mathbf{f}$ ).

Iron treatment resulted in a progressive decline in the hepatocyte densities from $1433.33 / \mathrm{mm}^{2}$ at day 16 to 1383.33 and $689.89 / \mathrm{mm}^{2}$ at day 32 and 49 respectively $(\mathrm{p}<0.001)$. Time matched mice treated with iron and ALA showed higher hepatocyte densities compared with the mice treated with iron alone $(\mathrm{p}<0.001)$. The densities for the mice treated with iron and ALA were 1572.22, 1583.33 and $1055.56 / \mathrm{mm}^{2}$ at day 16,32 and 49 respectively (Figure 5).

\section{Discussion}

ALA reduced the hepatic iron deposition in a manner similar to previous studies using related compounds. For instance, Gao et al. ${ }^{[19]}$ reported a reduction in iron deposition on the mouse liver using danshen, an antioxidant compound. The reduction in iron deposition with ALA treatment could be attributed to its iron chelating properties. ${ }^{[20]}$ This is a similar mechanism to that of deferoxamine and deferipone, known iron chelators that have been shown to reduce hepatic iron deposition in mice liver following iron overload. ${ }^{[21]}$ The dithiolane ring in the chemical structure of ALA confers its ability to bind redox active elements such as iron. ${ }^{[20,2]}$ Since generation of ROS directly correlates with the concentration of free intracellular iron, ${ }^{[23]}$ administration of ALA to iron overload patients could help chelate this free intracellular iron and thus reduce ROS generation and hepatic damage.

ALA treatment, as with other interventions reported elsewhere, resulted in a reduction in the parenchymal

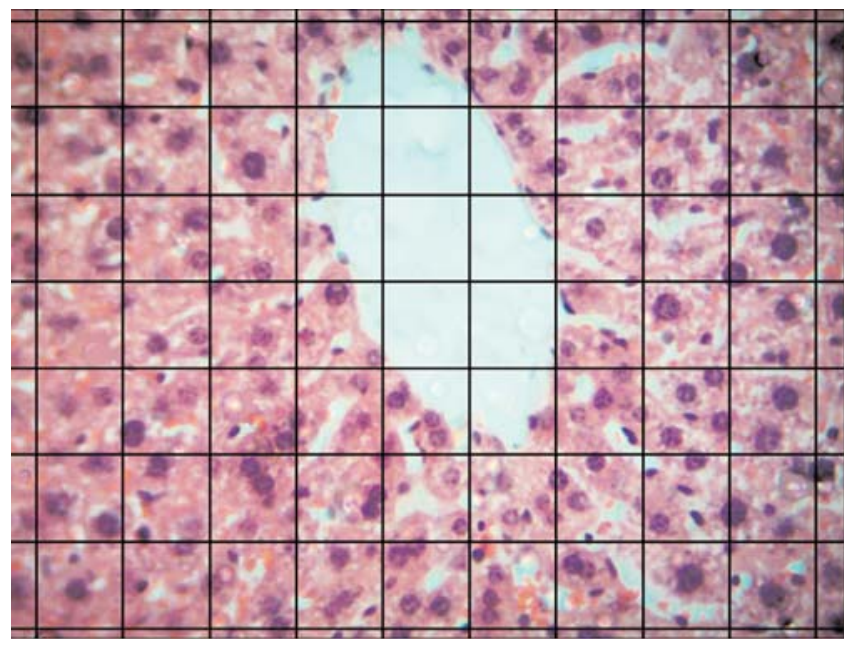

Figure 2. The grids used in the determination of hepatocyte densities The unit area for each grid square was $0.0018 \mathrm{~mm}^{2}$. Every second square on the grid was selected for cell counting and a total of 12 grid squares per field were considered. The average cellular count $/ \mathrm{mm}^{2}$ of the 12 unit areas was then used as the cell density. [Color figure can be viewed in the online issue, which is available at www.anatomy.org.tr]

damage seen with iron overload. Hazra et al. ${ }^{[24]}$ noted that a flavonoid compound, Katha, was protective against iron overload induced liver damage, while Sarkar et al. ${ }^{[25]}$ studied the effects of Emblica officinalis, an antioxidant, on the mouse liver following iron overload, and also noted an improvement in the histoarchitecture compared with iron treatment alone. The reduction in parenchymal damage may be attributed to the antioxidant capacity of ALA which makes it able to scavenge ROS produced during iron overload ${ }^{[26]}$ Systemic ALA has been shown to be protective against light induced oxidative retinal damage, supporting its protective effects against oxidative damage. ${ }^{[27]}$ This is further supported by

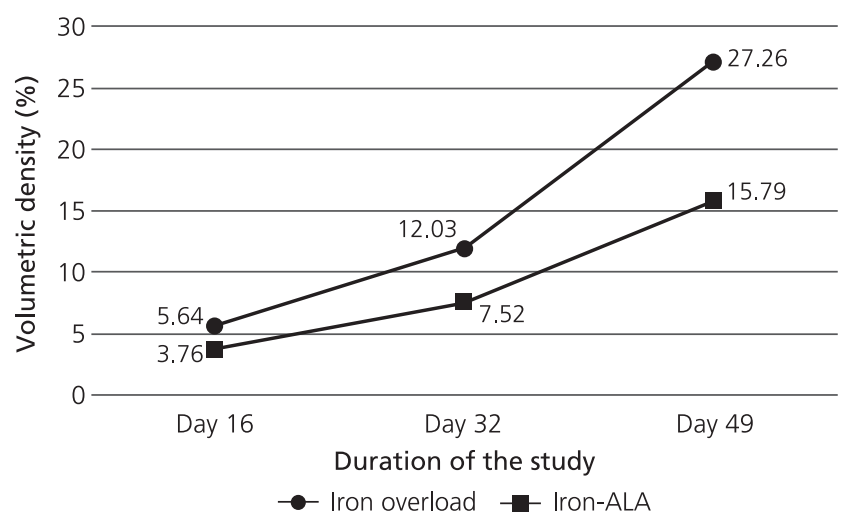

Figure 3. Line graph showing the volumetric densities of the iron deposits in the mouse liver tissue. 

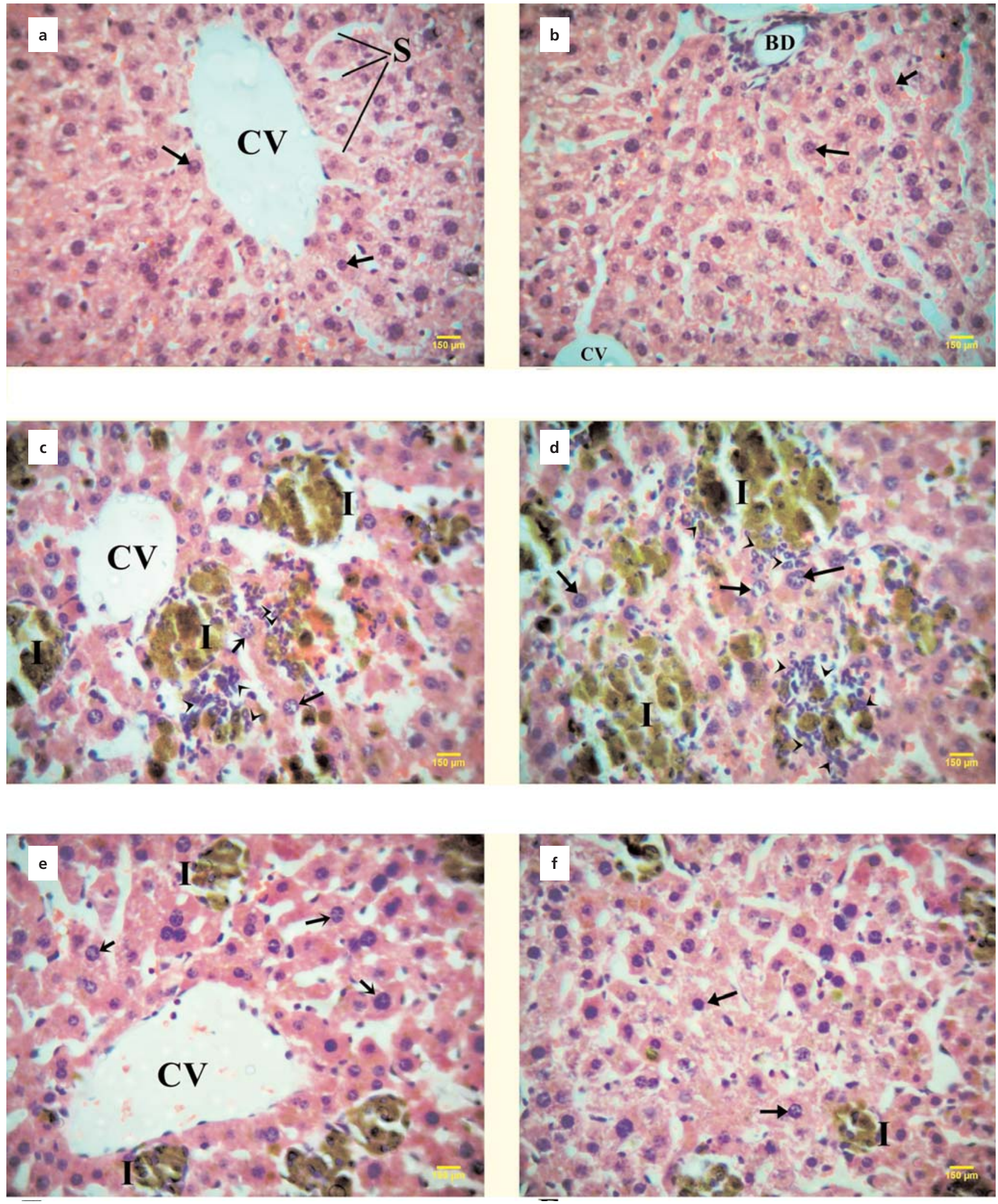

Figure 4. (a-f) Figure showing the histo-morphological changes in the livers of the control and experimental mice; (a, b) Liver of a normal control mouse; (c, d) Liver of a mouse treated with iron dextran for 49 days; (e, f) liver of a mouse treated with iron and ALA for 49 days. BD: bile duct; CV: central vein; I: iron deposits; S: sinusoids; arrows: hepatocyte nuclei; arrowheads: leukocyte infiltrates. Scale bar=150 $\mu \mathrm{m}$. [Color figure can be viewed in the online issue, which is available at www.anatomy.org.tr] 


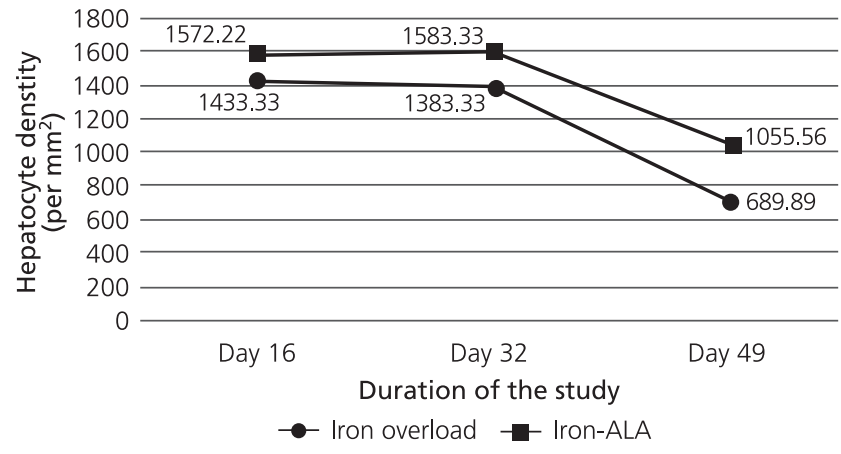

Figure 5. Line graph depicting the changes in hepatocyte densities in the mouse liver tissue.

the works of Rezk and Abdel-Rahman, ${ }^{[28]}$ who found ALA to be protective against lead and gamma-irradiation induced oxidative damage to the lungs and kidneys of albino rats. Additionally, it is postulated that ALA has the ability to regenerate other endogenous antioxidants such as Vitamin C, E and glutathione. ${ }^{[29-31]}$ For instance, biosynthesis of glutathione requires cysteine, an amino acid which is enhanced by ALA through the acceleration of the conversion of cystine to cysteine. ${ }^{[30]}$

Previous studies have shown that iron overload induced hepatocellular damage causes hepatic dysfunction which is alleviated by application of deferoxamine, an iron chelator ${ }^{[19,32]}$ Due to its potential iron chelating and antioxidant property, ALA could therefore be used to prevent hepatic cellular damage and subsequent dysfunction in iron overload conditions.

\section{Conclusion}

ALA considerably attenuates the structural damage in the liver induced by iron overload. We recommend further clinical studies to investigate the possible utility of ALA in the management of iron overload patients.

\section{References}

1. Hentze MW, Muckenthaler MU, Galy B, Camaschella C. Two to tango: regulation of mammalian iron metabolism. Cell 2010;142:2438.

2. Siddique A, Kowdley KV. Review article: the iron overload syndromes. Aliment Pharmacol Ther 2012;35:876-93.

3. Kohgo Y, Ikuta K, Ohtake T, Torimoto Y, Kato J. Body iron metabolism and pathophysiology of iron overload. Int $\mathrm{J}$ Hematol 2008;88:7-15.

4. Hershko C. Iron chelation therapy. New York (NY): Springer; 2012. $28-36$.

5. Sheth S. Iron chelation: an update. Curr Opin Hematol 2014;21: 179-85.
6. Brissot P. Optimizing the diagnosis and the treatment of iron overload diseases. Expert Rev Gastroenterol Hepatol 2016;10:359-70.

7. Mobarra N, Shanaki M, Ehteram H, Nasiri H, Sahmani M, Saeidi M, Goudarzi M, Pourkarim H, Azad M. A review on iron chelators in treatment of iron overload syndromes Int J Hematol Oncol Stem Cell Res 2016;10:239-47.

8. Assi TB, Baz E. Current applications of therapeutic phlebotomy. Blood Transfus 2014;12:75-83.

9. Ziegler D, Nowak H, Kempler P, Vargha P, Low PA. Treatment of symptomatic diabetic polyneuropathy with the antioxidant alphalipoic acid: a meta analysis. Diabet Med 2004;21:114-21.

10. Goralska M, Dackor R, Holley B, McGahan MC. Alpha lipoic acid changes iron uptake and storage in lens epithelial cells. Exp Eye Res 2003;76:241-8.

11. Suh JH, Moreau R, Heath SH, Hagen TM. Dietary supplementation with (R)- $\alpha$-lipoic acid reverses the age-related accumulation of iron and depletion of antioxidants in the rat cerebral cortex. Redox Rep 2005;10:52-60.

12. Zhang Y, Zhang Y, Xie Y, Gao Y, Ma J, Yuan J, Li J, Wang J, Li L, Zhang J, Chu L. Multitargeted inhibition of hepatic fibrosis in chronic iron-overloaded mice by Salvia miltiorrbiza. J Ethnopharmacol 2013;148:671-81.

13. Budin SB, Othman F, Louis SR, Bakar MA, Radzi M, Osman K, Das S, Mohamed J. Effect of alpha lipoic acid on oxidative stress and vascular wall of diabetic rats. Rom J Morphol Embryol 2009;50:23-30.

14. Ahmadvand H, Jamor P. Effects of alpha lipoic acid on level of NO and MPO activity in diabetic rats. Annals of Research in Antioxidants 2017;2:4-7.

15. Marcos R, Monteiro RA, Rocha E. The use of design-based stereology to evaluate volumes and numbers in the liver: a review with practical guidelines. J Anat 2012;220:303-17.

16. Mandarim-de-Lacerda CA. Stereological tools in biomedical research. An Acad Bras Cienc 2003;75:469-86.

17. Gundersen HJ, Bagger P, Bendtsen TF, Evans SM, Korbo LX, Marcussen N, Møller A, Nielsen K, Nyengaard JR, Pakkenberg B, Sørensen FB. The new stereological tools: disector, fractionator, nucleator and point sampled intercepts and their use in pathological research and diagnosis. APMIS 1988;96:857-81.

18. Bancroft JD, Cook HC. Manual of histological techniques and their diagnostic application. London (UK): Churchill Livingstone; 1994. p. 35-67.

19. Gao Y, Wang N, Zhang Y, Ma Z, Guan P, Ma J, Zhang Y, Zhang $\mathrm{X}$, Wang J, Zhang J, Chu L. Mechanism of protective effects of danshen against iron overload-induced injury in mice. J Ethnopharmacol 2013;145:254-60.

20. Shay KP, Moreau RF, Smith EJ, Smith AR, Hagen TM. Alphalipoic acid as a dietary supplement: molecular mechanisms and therapeutic potential. Biochim Biophys Acta 2009;1790:1149-60.

21. Yatmark P, Morales NP, Chaisri U, Wichaiyo S, Hemstapat W, Srichairatanakool S, Svasti S, Fucharoen S. Iron distribution and histopathological characterization of the liver and heart of $\beta$-thalassemic mice with parenteral iron overload: effects of deferoxamine and deferiprone. Exp Toxicol Pathol 2014;66:333-43.

22. Altintoprak N, Aydin S, Sanli A, Bilmez ZE, Kösemihal E. The protective effect of intratympanic alpha lipoic acid on cisplatin-induced ototoxicity on rats. J Int Adv Otol 2014;10:217-21.

23. Fernandes MS, Rissi TT, Zuravski L, Mezzomo J, Vargas CR, Folmer V, Soares FA, Manfredini V, Ahmed M, Puntel RL. Oxidative stress and labile plasmatic iron in anemic patients following blood therapy. World J Exp Med 2014;4:38-45. 
24. Hazra B, Sarkar R, Ghate NB, Chaudhuri D, Mandal N. Study of the protective effects of Katha (heartwood extract of Acacia catechu) in liver damage induced by iron overload. J Environ Pathol Toxicol Oncol 2013;32:229-40.

25. Sarkar R, Hazra B, Mandal N. Amelioration of iron overloadinduced liver toxicity by a potent antioxidant and iron chelator, Emblica officinalis Gaertn. Toxicol Ind Health 2015;31:656-69.

26. Al-Attar AM. Physiological and Histopathological Investigations on the Effects of $\alpha$-Lipoic Acid in Rats Exposed to Malathion. BioMed Res Int 2010;2010:203503

27. Zhao L, Wang C, Song D, Li Y, Song Y, Su G, Dunaief JL. Systemic administration of the antioxidant/iron chelator $\alpha$-lipoic acid protects against light-induced photoreceptor degeneration in the mouse retina. Invest Ophthalmol Vis Sci 2014;55:5979-88.

28. Rezk RG, Abdel-Rahman NA. Protective effects of lipoic acid against oxidative stress induced by lead acetate and gamma-irradia- tion in the kidney and lung in albino rats. Arab Journal of Nuclear Sciences and Applications 2013;46:324-37.

29. Biewenga GP, Haenen GR, Bast A. The pharmacology of the antioxidant lipoic acid. Gen Pharmacol 1997;29:315-31.

30. Suh JH, Wang H, Liu RM, Liu J, Hagen TM. (R)- $\alpha$-Lipoic acid reverses the age-related loss in GSH redox status in post-mitotic tissues: evidence for increased cysteine requirement for GSH synthesis. Arch Biochem Biophys 2004;423:126-35.

31. Zhang J, Zhou X, Wu W, Wang J, Xie H, Wu Z. Regeneration of glutathione by --lipoic acid via Nrf2/ARE signaling pathway alleviates cadmium-induced HepG2 cell toxicity. Environ Toxicol Pharmacol 2017;51:30-7.

32. Liu D, He H, Yin D, Que A, Tang L, Liao Z, Huang Q, He M. Mechanism of chronic dietary iron overload-induced liver damage in mice. Mol Med Rep 2013;7:1173-9.

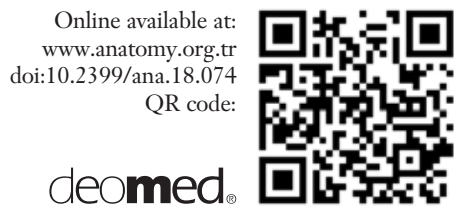

\author{
Correspondence to: William O. Sibuor \\ Department of Human Anatomy, School of Medicine, \\ University of Nairobi, Nairobi, Kenya \\ Phone: +25402318262 \\ e-mail:williamsibuor@gmail.com \\ Conflict of interest statement: No conflicts declared.
}

This is an open access article distributed under the terms of the Creative Commons Attribution-NonCommercial-NoDerivs 3.0 Unported (CC BY-NCND3.0) Licence (http://creativecommons.org/licenses/by-nc-nd/3.0/) which permits unrestricted noncommercial use, distribution, and reproduction in any medium, provided the original work is properly cited. Please cite this article as: Sibuor WO, Gwala FO, Munguti JK, Obimbo MM. Alpha-lipoic acid attenuates iron overload-induced structural changes in the liver of the laboratory mouse (Mus musculus). Anatomy 2018;12(3):118-123. 